\title{
Morphology of NdFeB-Type Permanent Magnet Coercivity Enhancement by Heat Treatment Process
}

\author{
Eva Afrilinda ${ }^{{ }^{*}}$, Dagus Resmana Djuanda ${ }^{1}$, Shinta Virdhian $^{1}$, Martin Doloksaribu ${ }^{1}$, Moch Iqbal Zaelana \\ Muttahar $^{1}$, and Sri Bimo Pratomo ${ }^{2}$
}

${ }^{1}$ Metal Industries Development Center (MIDC), Ministry of Industry of The Republic of Indonesia, Jl. Sangkuriang No. 12, Bandung 40135, West Java, Indonesia

${ }^{2}$ Department of Metallurgical Engineering, Faculty of Manufacturing Technology, Universitas Jenderal Achmad Yani, Jl. Terusan Jenderal Gatot Subroto, PO Box 807, Bandung 40285, West Java, Indonesia

\section{*Corresponding author:}

tel: $+62-22-2503171$

email: eva.afrilinda@gmail.com

Received: August 28, 2020

Accepted: November 9, 2020

DOI: $10.22146 / \mathrm{ijc} .59096$

\begin{abstract}
To understand the morphology of the coercivity enhancement by heat treatment, a commercial sintered NdFeB-type permanent magnet is annealed, and the coercivity is measured by Permagraph. It is shown that the coercivity is increased compared to the initial. Observation by X-Ray Diffraction (XRD) analysis and Scanning Electron Microscope-Energy Dispersive X-ray Spectroscopy (SEM-EDS) is then conducted. The XRD result shows the amount of $N d F e B$ content in the NdFeB-type permanent magnet is increased after heat treatment. The more significant amount of $\mathrm{NdFeB}$ content causes higher coercivity. The maximum coercivity, $19 \mathrm{kOe}$, is achieved at $850^{\circ} \mathrm{C}$ of heat treatment temperature, where the $\mathrm{NdFeB}$ content is at the highest amount. Microstructural characterizations using SEM-EDS show that at $850^{\circ} \mathrm{C}$ of heat treatment temperature, the iron ( $\mathrm{Fe}$ ) content in the grain boundaries is the lowest. It causes higher coercivity. This is due to the magnetically decoupled between NdFeB grains. The decoupling magnet of the $\mathrm{NdFeB}$ grains is affected by the Fe content in the grain boundaries. High-temperature heat treatment at 900 and $1050{ }^{\circ} \mathrm{C}$ led to the decomposition of $\mathrm{NdFeB}$ content in the grains and increased the Fe content in the grain boundaries, which resulted in a substantial reduction of magnetic coercivity.
\end{abstract}

Keywords: NdFeB; heat treatment; coercivity; magnetically decoupled; decomposed

\section{- INTRODUCTION}

One of the sintered magnets which can produce high energy $(\mathrm{BH})_{\max }$ is $\mathrm{Nd}-\mathrm{Fe}-\mathrm{B}$ sintered magnets. These magnets were made by Sepehri-Amin et al. [1]. Nd-Fe-B sintered magnets are utilized for different applications, e.g., voice coil motors for hard disk drives and engines for hybrid electric vehicles (HEVs) or electric vehicles (EVs). Ecological issues caused by carbon emission affected the developing business sector of an electric vehicle, so that HEVs and EVs have drawn a great deal of consideration to be produced. Even though Nd-Fe-B sintered magnets have high $(\mathrm{BH})_{\max }$, it has low intrinsic coercivity. This is contributed by the $\mathrm{Nd}_{2} \mathrm{Fe}_{14} \mathrm{~B}$ compound, the prime phase of this magnet, which arrives at around $12 \%$ of the anisotropy field of its prime phase [2]. The methods used to keep up high magnetic properties at the hightemperature environments in HEVs, are additional Dy or $\mathrm{Tb}$ into the $\mathrm{Nd}-\mathrm{Fe}-\mathrm{B}$ sintered magnets. It will create $\mathrm{Dy}_{2} \mathrm{Fe}_{14} \mathrm{~B}$ and $\mathrm{Tb}_{2} \mathrm{Fe}_{14} \mathrm{~B}$ compounds with a higher anisotropy field than $\mathrm{Nd}_{2} \mathrm{Fe}_{14} \mathrm{~B}$ [3].

Additional of Dy gives the Nd-Fe-B sintered magnets with several transformations such as better thermal stability but reduces the remanence and $(\mathrm{BH})_{\max }$ value [4]. Besides, these added substance components are quite rare to be found, and their material costs rise significantly. If the perfect coercivity of $\mathrm{Nd}_{2} \mathrm{Fe}_{14} \mathrm{~B}$ is acquired, the thermal ability would be improved without the addition of any substantial rare earth components. To attain high coercivity, two strategies have been proposed. 
One is to get uniform distribution of the Nd-rich stage, which helps to diminish the nucleation site of reversed magnetic domains. If there are found some imperfections on the outer of the $\mathrm{Nd}_{2} \mathrm{Fe}_{14} \mathrm{~B}$ grains, the reversed magnetic domains will show up at the low reverse magnetic field. Once a reversed magnetic domain appears in the grain, the domain wall moves, and magnetic reversal occurs without any problem. When a switched attractive space shows up in the grain, the area divider moves, and attractive inversion happens without any problem. In this case, it is required to diminish defects at the outer of $\mathrm{Nd}_{2} \mathrm{Fe}_{14} \mathrm{~B}$ grains to increase the coercivity value. The phase that plays a vital part in diminishing nucleation sites of the reversed magnetic domain amid the annealing process is the Nd-rich phase. This phase contributes to enhance the coercivity [5-6]. The other is to control grain sizes underneath the single domain size of $0.3 \mu \mathrm{m}$ in sintered magnets. These approaches appear that the control of microstructures of Nd-Fe-B magnets is very vital to get high coercivity [5].

Recently, sintered magnets with a grain measure around $1 \mu \mathrm{m}$ with $20 \mathrm{kOe}$ of coercivity, without the expansion of any heavy rare-earth elements were manufactured successfully on $\mathrm{Nd}-\mathrm{Fe}-\mathrm{B}$ type magnets by Sasaki et al. [7]. The methods to reduce the grain dimension are not the only reason to increase coercivity value. Subsequently, it is observed that Dy-free magnets with high coercivity were accomplished by reducing grain size, as well as reducing the nucleation sites of the reversed magnetic domain. Sepehri-Amin et al. [1] have researched the microstructure of the grain boundary for these magnets and the continuous grain boundary in sintered magnets through filtering electron microscopy (SEM), transmission electron microscopy (TEM), and atom probe tomography techniques. Moreover, they specified that the homogenous scattering of the Nd-rich phases at a triple junction was required to make a continuous grain boundary. Hence, the Nd-rich stage at the triple junction works as an asset to create grain boundary layers during the heat treatment process, particularly the annealing process [3].
It is notable that heat treatment of sintered Nd-FeB magnet emphatically builds the coercivity and improves the squareness of the demagnetizing $\mathrm{J} / \mathrm{H}$ loops [8]. The temperature and time of this heat treatment, called annealing, the composition of the magnet should be considered then followed by fast quenching to optimize both the intrinsic coercivity and the hysteresis loop squareness. Numerous researchers have portrayed the impact of the annealing treatment and demonstrated a few patterns to associate the coercivity increment with an appearing mechanism in the grain boundary of the $\mathrm{RE}_{2} \mathrm{Fe}_{14} \mathrm{~B}$ magnetic phase [9]. Nowadays, a few mechanisms are proposed. Some consider the impact of the RE-rich (RE: Rare Earth, for the most part, Ndboundary phase as magnetic protection of the $\mathrm{RE}_{2} \mathrm{Fe}_{14} \mathrm{~B}$ magnetic phase, and others ignore the participation of the boundary phase) [10].

There are necessarily two conceivable outcomes when it comes to creating coercivity at high temperatures. The outcomes are upgrading the intrinsic temperature reliance of the materials or creating sufficient coercivity value at room temperature to remain when the magnet is faced with high-temperature environments [11]. NdFeB magnets create their coercivity following a nucleation- type coercivity mechanism. It is crucial to locally increase the HA within the external shell of the grains, to the proximity of much less than a micron, as any new another rare earth in the $\mathrm{RE}_{2} \mathrm{Fe}_{14} \mathrm{~B}$ grains [12]. It will substantially decrease the value of the magnetization.

The purpose of this study was to use several experimental techniques to define the relationship between the optimized annealing conditions and metallurgical transformations, also the microstructure change due to annealing in the $\mathrm{NdFeB}$ grains and grain boundary phase. The test samples were prepared by several annealing conditions at various temperatures. The magnetic properties were then measured and analyzed by Permagraph, X-Ray Diffraction (XRD), and Scanning Electron Microscope (SEM)-EnergyDispersive X-ray Spectroscopy (EDS) observations. 


\section{- EXPERIMENTAL SECTION}

\section{Materials}

The material used in this experiment was a commercial NdFeB-type permanent magnet sample that has an initial coercivity of $13.7 \mathrm{kOe}$, which compositions are listed in Table 1.

\section{Instrumentation}

Instruments used included SANTE-High Temperature Vacuum Tube Furnace, Lab made grinding and polishing machine, Permagraph Magnet Physik, JEOL SEM machine type JSM636OLA, and Maxima XRD machine.

\section{Procedure}

The un-magnetized samples were cut to the dimension of $12 \times 12 \times 5 \mathrm{~mm}$ and then put into the argonfilled vacuum heat treatment furnace. Afterward, they were annealed using several annealing conditions and various temperatures. The annealing temperature is set at $800,850,900,950,1000$, and $1050{ }^{\circ} \mathrm{C}$ and held for $2 \mathrm{~h}$. Subsequently, the post-annealing temperature is set at $500{ }^{\circ} \mathrm{C}$, also held for $2 \mathrm{~h}$. The heat treatment cycle of this research is shown in Fig. 1.

The value of magnetic coercivity is obtained by permagraph observation, which measures the reverse magnetic field that is applied to the sample, which changes the magnetized sample into fully demagnetized. Meanwhile, the chemical composition and metallurgical transformations appearing in the grains and grain boundary of the $\mathrm{RE}_{2} \mathrm{Fe}_{14} \mathrm{~B}$ magnetic phase are observed by $\mathrm{X}$-Ray Diffraction (XRD) and Scanning Electron
Microscope (SEM)/Energy-Dispersive X-ray Spectroscopy (EDS).

\section{- RESULTS AND DISCUSSION \\ Permagraph Result Analysis}

$\mathrm{NdFeB}$-phase is the main element of the magnetic force in the NdFeB-type permanent magnet. The amount of $\mathrm{NdFeB}$ is related to high coercivity. The more of NdFeB contained, the higher coercivity is achieved. The presence of $\mathrm{NdFeB}$-phase can be produced by casting $\mathrm{NdFeB}$ alloy. However, not all the elements are combined to developed NdFeB-phase by casting only; many of them are spread out become $\alpha-\mathrm{Fe}, \mathrm{Nd}$ Rich, FeB, and so on. The Heat treatment for NdFeB-type permanent magnet is one of the processes that can be conducted to recombine the spread out elements into developing new NdFeB-phases.

The permagraph result shows that magnetic coercivity is increased after the heat treatment process. It is noticed that the highest coercivity ( $19 \mathrm{kOe})$ is achieved at $850{ }^{\circ} \mathrm{C}$ of annealing temperature [13]. Afterward, the coercivity is gradually decreased when the temperature is increased, but still higher than the initial coercivity, shown in Fig. 2.

Table 1. Composition of commercial NdFeB-type permanent magnet for the experiment

\begin{tabular}{clc}
\hline No. & \multicolumn{1}{c}{ Element } & wt (\%) \\
\hline 1 & Nd (Neodymium) & 28.07 \\
2 & Fe (Iron) & 70.2 \\
3 & B (Boron) & 1.1 \\
4 & Nb (Niobium) & 0.3 \\
5 & Ga (Gallium) & 0.33 \\
\hline
\end{tabular}

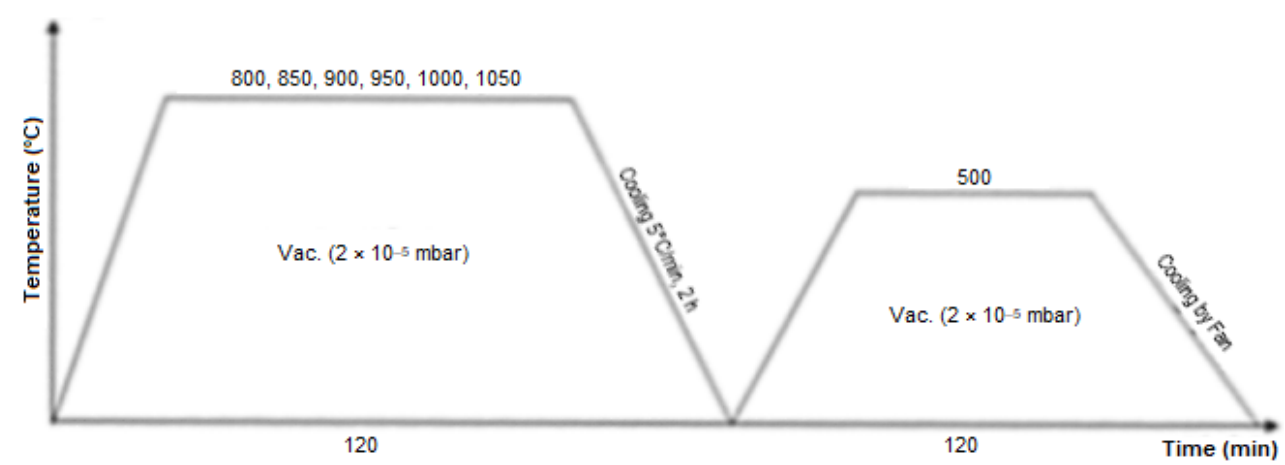

Fig 1. Variable of time and temperature for heat treatment process 


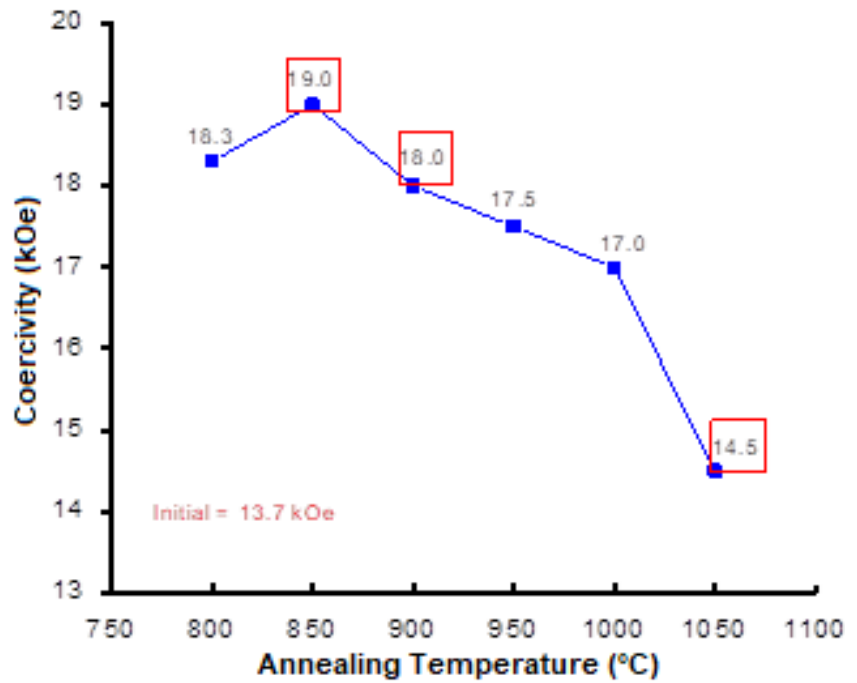

Fig 2. The change of coercivity at increased annealing temperature

The selected temperatures for the characterization of this research in the microstructure phase by XRD and microstructure composition by SEM from samples after heat treatment are at 850,900 , and $1050{ }^{\circ} \mathrm{C}$ are conducted and analyzed. The temperatures 850 and $1050{ }^{\circ} \mathrm{C}$ are selected because they show the highest and lowest coercivity, respectively. The $900{ }^{\circ} \mathrm{C}$ annealing temperature presents a condition where the coercivity is starting to decrease. The annealing condition at 800,950 , and $1000{ }^{\circ} \mathrm{C}$ are not being analyzed any further since $800^{\circ} \mathrm{C}$ is already represented by initial coercivity, which is before optimum temperature. The $850{ }^{\circ} \mathrm{C}$ annealing condition is very important, because at this temperature, the coercivity is at the maximum value. Because the decrease of coercivity is already started at $900{ }^{\circ} \mathrm{C}$, after optimum condition at $850{ }^{\circ} \mathrm{C}$, the $950{ }^{\circ} \mathrm{C}$ annealing condition will not be significant anymore. The $1050{ }^{\circ} \mathrm{C}$ annealing condition, where the coercivity is the lowest, has a significant difference in the data compare to $1000^{\circ} \mathrm{C}$. By having data at optimum condition $\left(850^{\circ} \mathrm{C}\right)$, before optimum condition (initial), and after optimum condition $\left(900\right.$ and $\left.1050^{\circ} \mathrm{C}\right)$, the discussion is compact and comprehensive.

Annealing temperature and annealing time are the crucial parameters for controlling grain development. The crystallizations are depending on the composition [14]. With quick annealing tempering of $60 \mathrm{~s}$ at $500{ }^{\circ} \mathrm{C}$, it is conceivable to get the grain sizes of $50 \mathrm{~nm}$ and a coercive field Hc up to $20 \mathrm{kOe}$ [15].

\section{XRD Result Analysis}

The XRD results in Fig. 3 show a phase-change in the samples after the heat treatment process. At $850^{\circ} \mathrm{C}$, which is the optimum temperature for coercivity enhancement, contain the highest amount of NdFeBphase [16]. A compelling way to extend coercivity is to decrease the grain size underneath the single domain particle size. This can be frequently found in $\mathrm{NdFeB}$ layers, where the size is indeed more significant than the lateral grain size [17]. The switchover of coupling between neighboring grains leads to the interaction for each domain. For the most part, the domain walls will take after the grain boundaries, illustrating their pinning impact. In this manner, the coercivity enhancement follows the decline of grain size and the magnetically decouple of the closest grains.

From the XRD analysis result, it is described that there are phase-changed in the samples after heat treatment. The amount of NdFeB-phase is increased after heat treatment at $850{ }^{\circ} \mathrm{C}$. However, when the heat treatment temperature is set at a higher temperature $\left(900,1050{ }^{\circ} \mathrm{C}\right)$, the coercivity is decreased due to the decomposition of the NdFeB-phase. Table 2 shows the change of coercivity value because of the NdFeB-phase composition amount.

In $\mathrm{Nd}-\mathrm{Fe}-\mathrm{B}$ sintered magnets, there are several secondary phases, such as $\alpha-\mathrm{Fe}, \mathrm{NdFe}$ (Nd-rich), $\mathrm{FeB}$, and

Table 2. The relation between phase composition and coercivity

\begin{tabular}{lrlrccc}
\hline \multirow{2}{*}{ Samples } & \multicolumn{5}{c}{ Phase composition (\%) } & \begin{tabular}{c} 
Coercivity samples \\
\cline { 2 - 5 }
\end{tabular} \\
\cline { 2 - 5 } & \multicolumn{1}{c}{$\mathrm{Fe}$} & $\mathrm{Nd}$ & $\mathrm{NdFe}$ & $\mathrm{FeB}$ & $\mathrm{FeB}$ & \\
\hline Initial & 2.1 & 0.3 & 5.2 & 92.3 & 0.1 & 13.7 \\
$850^{\circ} \mathrm{C}$ & 25.2 & 3.1 & 14.5 & 13.2 & 44 & 19 \\
$900^{\circ} \mathrm{C}$ & 5.5 & 0.6 & 9.8 & 76.7 & 7.4 & 17.5 \\
$1050^{\circ} \mathrm{C}$ & 21.5 & 0 & 73.1 & 3.7 & 1.6 & 14.5 \\
\hline
\end{tabular}

Eva Afrilinda et al. 


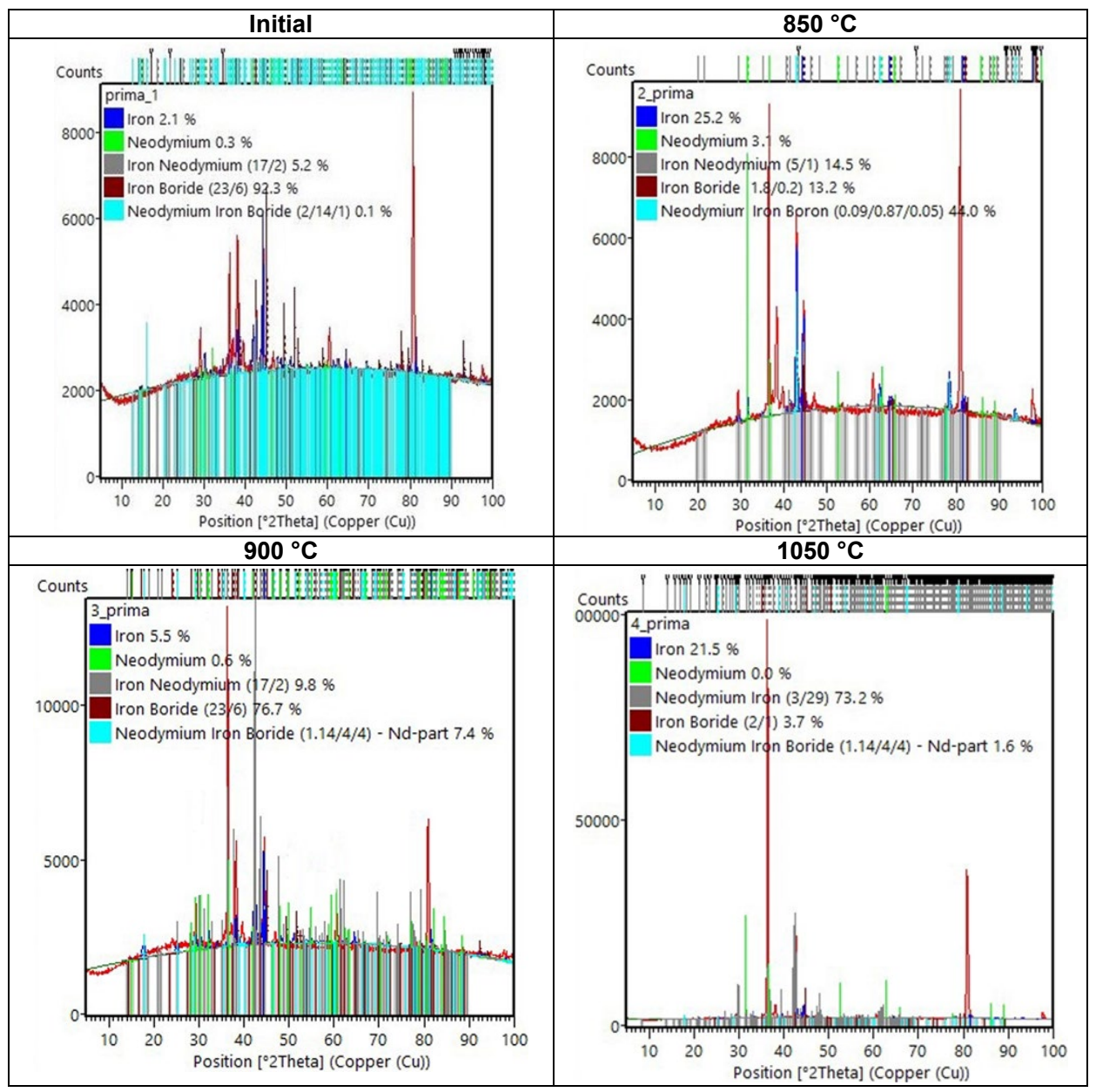

Fig 3. Phase-change at samples after heat treatment process by XRD

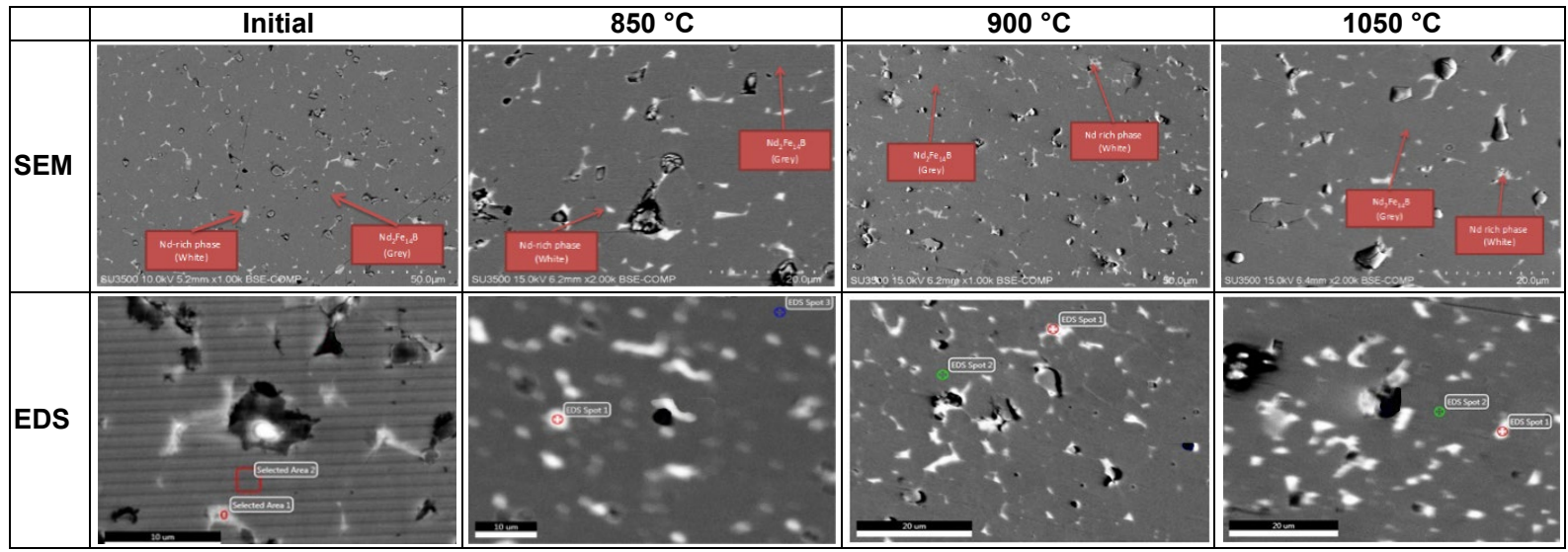

Fig 4. Microstructure of samples after heat treatment by SEM

oxides [18]. At the $850{ }^{\circ} \mathrm{C}$ annealing temperature, those secondary phase compositions are transformed into new $\mathrm{NdFeB}$-phase. These cause an increase of coercivity due to the increased annealing temperature.

\section{SEM-EDS Result Analysis}

The SEM observation results of samples after heat treatment are shown in Fig. 4. The images point to a grey and white area. The grey area represents the $\mathrm{NdFeB}$ grain, 
and the white area represents grain boundaries [19-20].

The EDS results show that the composition in the grey area and white area. Fig. 5 shows the composition content of the grey area and white area, where the rareearth and Fe composition are shown in Table 3.
The white area is representing the grain boundaries. The lowest Fe content (12.22\%) in the grain boundaries is observed at $850{ }^{\circ} \mathrm{C}$, as shown in Table 3 . When the $\mathrm{Fe}$ content is low, the grain will be considered as magnetically separated (magnetic decoupling) that gives

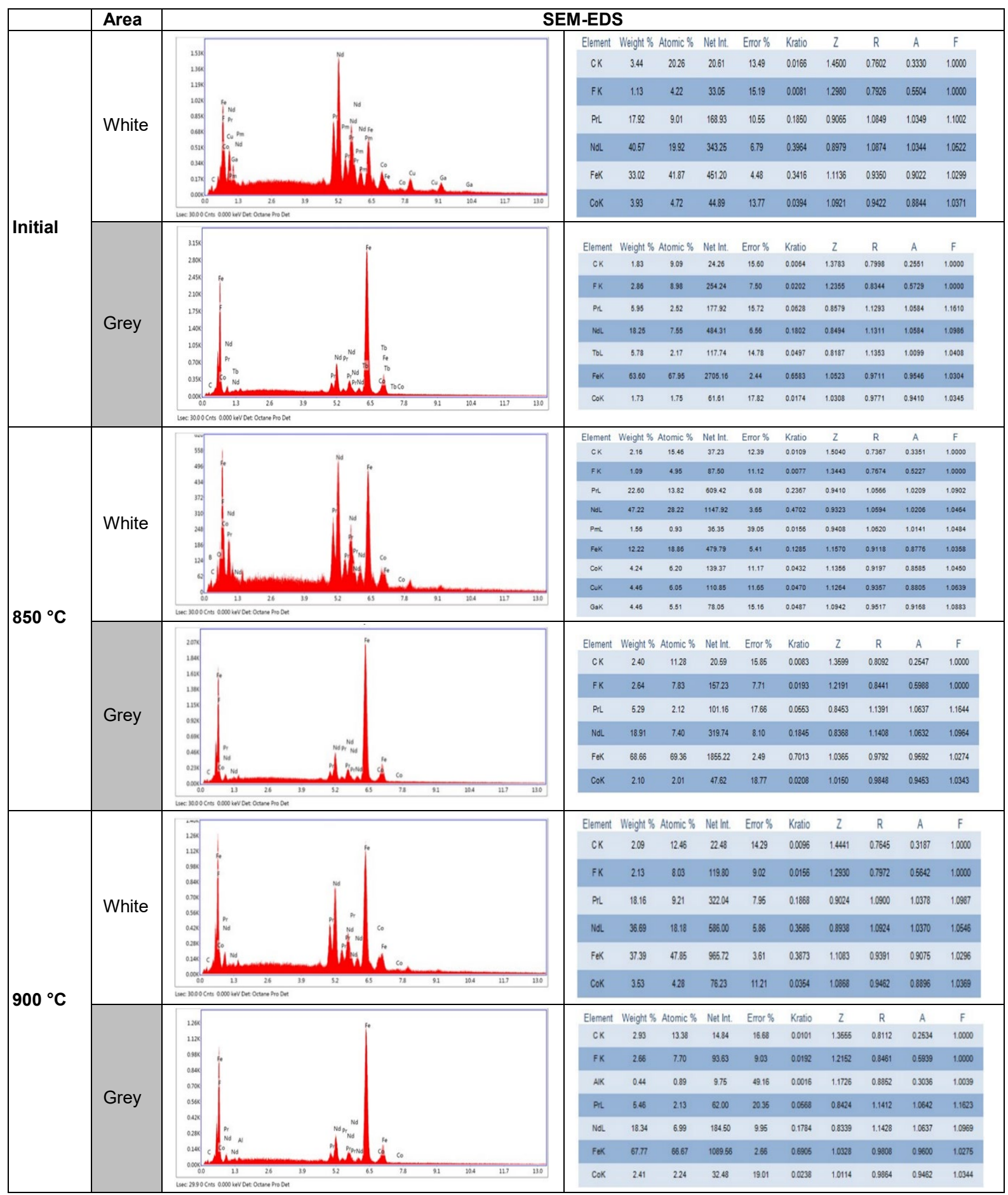

Fig 5. Composition of white and grey area in the sample after heat treatment by EDS 


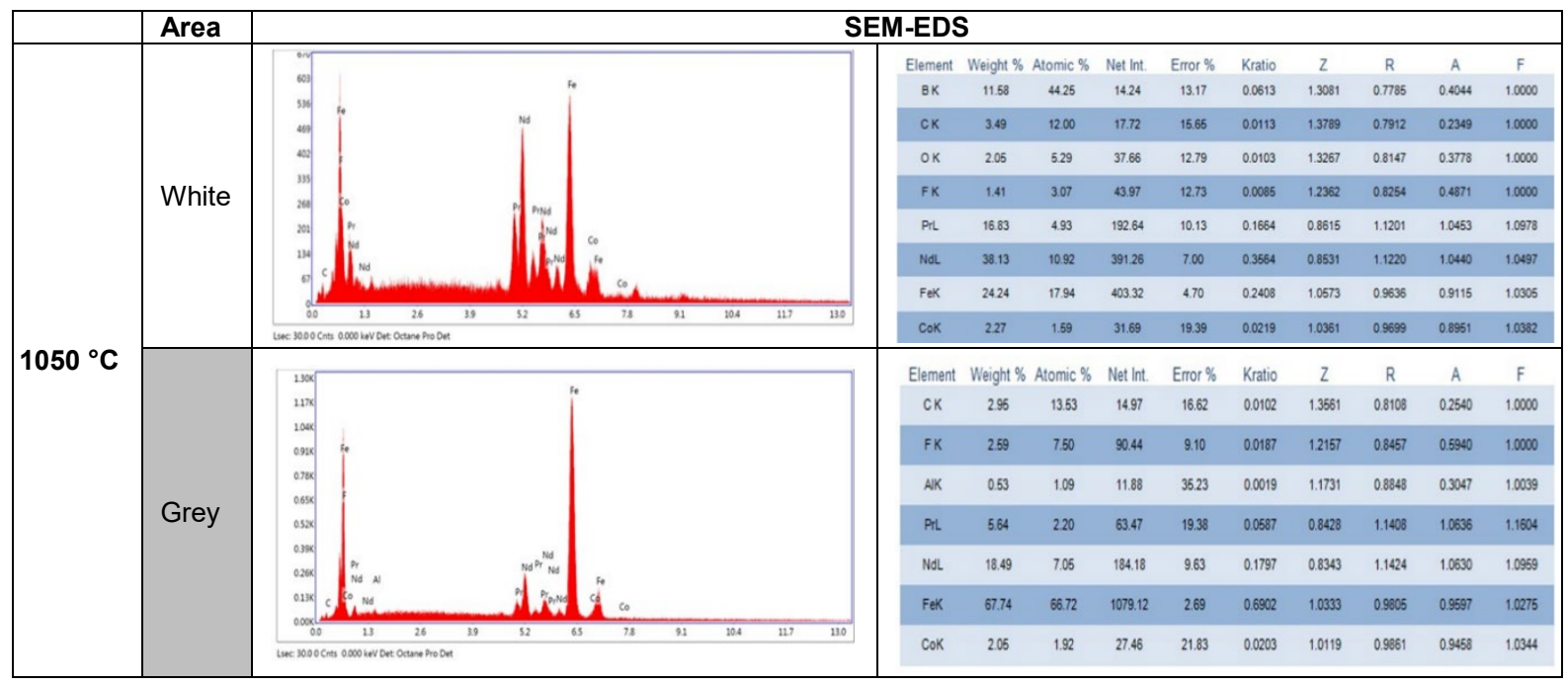

Fig 5. Composition of white and grey area in the sample after heat treatment by EDS (Continued)

Table 3. Composition of Rare-Earth (RE) and Fe in white and grey area of the sample after heat treatment by EDS

\begin{tabular}{lcccccccc}
\hline \multirow{2}{*}{ Area Color } & \multicolumn{8}{c}{ Composition (\%) } \\
\cline { 2 - 10 } & \multicolumn{2}{c}{ Initial } & \multicolumn{2}{c}{$850^{\circ} \mathrm{C}$} & \multicolumn{2}{c}{$900^{\circ} \mathrm{C}$} & \multicolumn{2}{c}{$1050{ }^{\circ} \mathrm{C}$} \\
\cline { 2 - 10 } & $\mathrm{RE}$ & $\mathrm{Fe}$ & $\mathrm{RE}$ & $\mathrm{Fe}$ & $\mathrm{RE}$ & $\mathrm{Fe}$ & $\mathrm{RE}$ & $\mathrm{Fe}$ \\
\hline White & 58.39 & 33.02 & 71.38 & 12.22 & 55.15 & 37.39 & 56.96 & 24.24 \\
Grey & 29.98 & 63.6 & 24.2 & 68.66 & 23.8 & 67.77 & 24.13 & 67.74 \\
\hline Coercivity (kOe) & \multicolumn{1}{c}{13.7} & \multicolumn{2}{c}{19} & \multicolumn{2}{c}{17.5} & 14.5 \\
\hline
\end{tabular}

high coercivity. On the other hand, when the Fe content in the white area is high $\left(37.39 \%\right.$ at $\left.900{ }^{\circ} \mathrm{C}\right)$, the coercivity is lower. These can be explained as Fe has high magnetic conductivity (ferromagnetic) [21]. If the grain boundaries have high Fe content, then the neighboring grains will be considered as one big grain that causes low coercivity.

Paramagnetic component addition, such as $\mathrm{RE}$ (Rare-Earth), in this case, neodymium in NdFeB, creates a neodymium-rich intergranular paramagnetic stage that decouples the ferromagnetic $\mathrm{NdFeB}$ grains. The decoupling avoids the nucleation initiated by the closest grains and heighten the coercivity. The highest RE content (71.38\%) in the grain boundaries is observed at $850{ }^{\circ} \mathrm{C}$, as shown in Table 3 . When the RE content is high, then the grain will be considered as magnetically separated (magnetic decoupling) that gives high coercivity. However, the grain size will shrink, and the energy production can be achieved effectively with neodymium concentrations higher than the stoichiometric composition [22].
A previous study in manipulating grain boundaries [23] shows that the continuous grain boundaries are developed after annealing, which causes the increase of magnetic coercivity for the NdFeB-type permanent magnet. Our study result compliments their data by defining the continuous grain boundaries crystal phase where the RE or Fe content in the grain boundaries gives a significant effect to coercivity value, as shown in Table 3. Further study is needed to determine the homogeneity of the metal distribution in the sample by Electron Probe Micro Analyzer (EPMA), despite localize measurement from EDS.

\section{- CONCLUSION}

From the experiments, it shows clearly that the coercivity enhancement of $\mathrm{NdFeB}$ type permanent magnet by heat treatment process is due to the increasing amount of NdFeB-phase in the grain and the magnetically separation between the neighboring grains. 
This result gives the necessary information for any effort in increasing the magnetic properties of NdFeB-type permanent magnet.

\section{- ACKNOWLEDGMENTS}

This research was financially supported by the Korean Institute of Materials Science (KIMS).

\section{- AUTHOR CONTRIBUTIONS}

All authors conducted the experiment, calculations, wrote, and revised the manuscript then agreed to the final version of this manuscript.

\section{- REFERENCES}

[1] Sepehri-Amin, H., Une, Y., Ohkubo, T., Hono, K., and Sagawa, M., 2011, Microstructure of fine-grained $\mathrm{Nd}-\mathrm{Fe}-\mathrm{B}$ sintered magnets with high coercivity, Scr. Mater., 65 (5), 396-399.

[2] Poenaru, I., Lixandru, A., Güth, K., Malfliet, A., Yoon, S., Škulj, I., and Gutfleisch, O., 2020, HDDR treatment of Ce-substituted $\mathrm{Nd}_{2} \mathrm{Fe}_{14} \mathrm{~B}$-based permanent magnet alloys - phase structure evolution, intergranular processes and magnetic property development, J. Alloys Compd., 814, 152215.

[3] Goto, R., Matsuura, M., Sugimoto, S., Tezuka, N., Une, Y., and Sagawa, M., 2012, Microstructure evaluation for Dy-free Nd-Fe-B sintered magnets with high coercivity, J. Appl. Phys., 111 (7), 07A739.

[4] Li, X., Liu, S., Cao, X., Zhou, B., Chen, L., Yan, A., and Yan, G., 2016, Coercivity and thermal stability improvement in sintered $\mathrm{Nd}-\mathrm{Fe}-\mathrm{B}$ permanent magnets by intergranular addition of Dy-Mn alloy, $J$. Magn. Magn. Mater., 407, 247-251.

[5] Soderžnik, M., Rožman, K.Ž., Kobe, S., and McGuiness, P., 2012, The grain-boundary diffusion process in Nd-Fe-B sintered magnets based on the electrophoretic deposition of $\mathrm{DyF}_{3}$, Intermetallics, 23, 158-162.

[6] Vial, F., Joly, F., Nevalainen, E., Sagawa, M., Hiraga, K., and Park, K.T., 2002, Improvement of coercivity of sintered $\mathrm{NdFeB}$ permanent magnets by heat treatment, J. Magn. Magn. Mater., 242-245 (Part 2), 1329-1334.
[7] Sasaki, T.T., Ohkubo, T., Hono, K., Une, Y., and Sagawa, M., 2013, Correlative multi-scale characterization of a fine grained $\mathrm{Nd}-\mathrm{Fe}-\mathrm{B}$ sintered magnet, Ultramicroscopy, 132, 222-226.

[8] Kim, S., Ko, D.S., Lee, H.S., Kim, D., Roh, J.W., and Lee, W., 2019, Enhancing the coercivity of Nd-Fe-B sintered magnets by consecutive heat treatmentinduced formation of Tb-diffused microstructures, J. Alloys Compd., 780, 574-580.

[9] Yin, W., Chen, R., Tang, X., Ju, J., and Yan, A., 2019, Effect of pressless heat treatment on the magnetic performance and microstructure of hot-deformed Nd-Fe-B magnet, J. Magn. Magn. Mater., 482, 9-13.

[10] Loewe, K., Benke, D., Kübel, C., Lienig, T., Skokov, K.P., and Gutfleisch, O., 2017, Grain boundary diffusion of different rare earth elements in Nd-FeB sintered magnets by experiment and FEM simulation, Acta Mater., 124, 421-429.

[11] Li, Y., Zhu, M., Li, A., Feng, H., Huang, S., Li, W., Du, A., and Qi, Y., 2014, Relationship between controllable preparation and microstructure of $\mathrm{NdFeB}$ sintered magnets, J. Rare Earths, 32 (7), 628-632.

[12] Liu, Y., Pan, Q., Li, H., Huang, Z., Ye, J., and Li, M., 2019, Revealing the evolution of microstructure, mechanical property and corrosion behavior of 7A46 aluminum alloy with different ageing treatment, J. Alloys Compd., 792, 32-45.

[13] Pratomo, S.B., Djuanda, D.R., Fauzi, M.N., Afrilinda, E., and Nurqiat, P.R., 2019, Peningkatan koersivitas magnet permanen tipe $\mathrm{Nd}_{2} \mathrm{Fe}_{14} \mathrm{~B}$ dengan metoda perlakuan panas, Jurnal Teknologi Bahan dan Barang Teknik, 9 (1), 1-6.

[14] Zhou, Q., Li, W., Hong, Y., Zhao, L., Zhong, X., Yu, H., Huang, L., and Liu, Z., 2018, Microstructure improvement related coercivity enhancement for sintered $\mathrm{NdFeB}$ magnets after optimized additional heat treatment, J. Rare Earths, 36 (4), 379-384.

[15] Krasny, Y.P., Kovalenko, N.P., and Krey, U., 1997, Thermodynamics of amorphous magnets with ferromagnetic and antiferromagnetic coupling, Physica B, 240 (1-2), 173-182. 
[16] Wang, Y., You, C., Wang, J., Tian, N., Lu, Z., and Ge, L., 2012, Coercivity enhancement of $\mathrm{Nd}_{2} \mathrm{Fe}_{14} \mathrm{~B} / \alpha-\mathrm{Fe}$ nanocomposite magnets through neodymium diffusion under annealing, J. Rare Earths, 30 (8), 757 760 .

[17] Gouteff, P.C., Folks, L., and Street, R., 1998, MFM study of $\mathrm{NdFeB}$ and $\mathrm{NdFeB} / \mathrm{Fe} / \mathrm{NdFeB}$ thin films, $J$. Magn. Magn. Mater., 177-181 (Part 2), 1241-1242.

[18] Li, J., Yang, D., and Zhu, X., 2017, Effects of aging time and annealing temperature on structural and optical properties of sol-gel $\mathrm{ZnO}$ thin films, AIP $A d v$., 7 (6), 065213.

[19] Zhou, L., Li, J., Cheng, X., Liu, T., Yu, X., and Li, B., 2017, Dy gradient and coercivity in grain boundary diffusion processed Nd-Fe-B magnet, J. Rare Earths,
35 (6), 559-566.

[20] Hu, S.Q., Peng, K., and Chen, H., 2017, Influence of annealing temperature on the Dy diffusion process in NdFeB magnets, J. Magn. Magn. Mater., 426, 340-346.

[21] Coey, J.M.D., 2011, Hard magnetic materials: A perspective, IEEE Trans. Magn., 47 (12), 4671-4681.

[22] Piramanayagam, S.N., Matsumoto, M., Morisako, A., and Takei, S., 1998, Studies on NdFeB thin films over a wide composition range, J. Alloys Compd., 281 (1), 27-31.

[23] Li, W.F., Ohkubo, T., and Hono, K., 2009, Effect of post-sinter annealing on the coercivity and microstructure of Nd-Fe-B permanent magnets, Acta Mater., 57 (5), 1337-1346. 